\title{
Factors Influencing the Cervical Cancer Screening uptake among Medical Lecturers at Faculty of Medicine Universitas Padjadjaran
}

\author{
Sri Yusnita Irda Sari, ${ }^{1}$ Phavithra Rathakirushnan, ${ }^{2}$ Edwin Armawan ${ }^{3}$ \\ ${ }^{1}$ Department of Public Health Faculty of Medicine Universitas Padjadjaran, Indonesia, ${ }^{2}$ Faculty of \\ Medicine Universitas Padjadjaran, Indonesia, ${ }^{3}$ Department of Obstetrics and Gynecology Faculty \\ of Medicine Universitas Padjadjaran/Dr. Hasan Sadikin General Hospital Bandung, Indonesia
}

\section{Abstract}

Background: Cancer is the leading cause of death worldwide. In Indonesia, cervical cancer is one of the most occurring types of cancer. It is acknowledged that early screening can prevent cervical cancer. This study aimed to explore what factors influenced the screening uptake and to correlate characteristics, perceived susceptibility, and self-efficacy of Pap smear uptake among medical faculty lecturers.

Methods: This was a cross-sectional analytical study conducted among female lecturers in the Faculty of Medicine, Universitas Padjadjaran from October to November 2013. The questionnaire was used to collect data using a purposive sampling method. Data collected were tabulated into frequency and percentage and the correlation was performed using Pearson chi-square.

Results: From a total of 79 respondents who participated, only 55.7\% of medical lecturers had ever taken Pap smear. Reasons for not taking Pap smear were time (77.1\%) and the perception of not being at risk (22.9\%). However, most of the respondents $(84.8 \%)$ were willing to have a screening test for cervical cancer routinely. There was a significant correlation between age $(p=0.001)$, level of education $(\mathrm{p}=0.003)$ and duration of marriage $(\mathrm{p}=0.001)$ with the uptake of Pap smear.

Conclusions: The factors that are influencing the uptake of screening are not having the time to take the test and the perception of not being at risk of the disease. There is a correlation between age, level of education and duration of marriage with screening uptake. Awareness of the importance of screening should also be promoted among female doctors.

Keywords: Awareness, cervical cancer, pap smear, screening

\section{Introduction}

Cervical cancer is the leading cause of death among women, occurring more commonly in under-developed and developing countries. ${ }^{1}$ Gynecological cancer is a type of cancer that arises in women's reproductive organs. ${ }^{2}$ Gynecological cancer arises with an increment in age, therefore early detection through screening and tests can decrease its incidence. ${ }^{2}$ Cervical cancer is placed as the second most common type of cancer in women. ${ }^{3}$ The highest rate of death caused by cervical cancer occurred among women in developing countries. ${ }^{3}$ In Indonesia ${ }^{4}$, cervical cancer seems to be the most occurring type of cancer and is positioned as the first followed by breast, ovary, skin, thyroid, rectum, lymph node, uterus, colon, and nasopharynx.

Cervical cancer is caused primarily by human papillomavirus (HPV). ${ }^{5}$ Continuous infection of the cervix with specific highrisk types of HPV is a prerequisite for the development of cervical cancer. ${ }^{6}$ There are two methods in preventing cervical cancer from occurring, one way is to find and treat the precancerous cells before they become cancerous (screening) and the other way is to prevent the pre-cancers in the beginning (vaccination). ${ }^{7}$ Detection of cervical cancer is performed in a

Correspondence: Sri Yusnita Irda Sari, Department of Public Health Faculty of Medicine, Universitas Padjadjaran, Jalan Eyckman No. 38 Bandung, Indonesia. E-mail: italatif@yahoo.com 
few ways, one of it is cytological screening and the management of the abnormal Papanicolau testing.7 According to the American Cancer Society, ${ }^{7}$ all women should start to get screened at the age of 21. It is recommended for women aged 30-65 to get Pap smear testing every 3 years. ${ }^{7}$

A study conducted in Uganda ${ }^{8}$ on medical workers in Muago Hospital showed that $81 \%$ of their staff have never been screened for cervical cancer. This shows that medical workers with a higher level of education do not necessarily practice screening methods for cervical cancer even though the awareness of cervical cancer is sufficient. ${ }^{8}$ A study conducted in Jamaica ${ }^{9}$ showed that the highest percentage of reason for not undergoing Pap smear test is that they have no symptoms and therefore perceive that they have no risk toward the disease. Most studies conducted on screening uptake have correlated knowledge level with screening uptake of Pap smear. Similar studies in the United States conclude that there is a high correlation between education and screening uptake. ${ }^{9}$

Therefore, this study was carried out to find out what were the factors that influenced the uptake of cervical cancer screening and to correlate the characteristics, perceived susceptibility and self-efficacy with the uptake of Pap smear among medical faculty lecturers.

\section{Methods}

This analytical study was carried out in October-November 2013 in the Faculty of Medicine Universitas Padjadjaran, Bandung, Indonesia. To evaluate the factors that influenced the uptake of Pap smear and the correlation between characteristics, perceived susceptibility and self-efficacy with the uptake of Pap smear among medical lecturers, a set of questionnaires consisted of 17 questions were distributed. Samples were collected using purposive sampling method. In total, 79 female medical faculty lecturers were selected after matching the study subjects using the inclusion and exclusion criteria. The inclusion criteria of the research were married lecturers who signed the informed consent; whereas the exclusion criteria were lecturers who previously underwent a total hysterectomy.

Based on the Health Belief Model theory ${ }^{10}$, two variables were assessed in this study; the independent variables which were the characteristics, perceived susceptibility and self-efficacy, and the dependent variable was the uptake of Pap smear. Informed consent was given to the respondents before handing out the questionnaires, which were given personally to each lecturer whenever they had free time and each respondent was given adequate time to answer the questionnaire. The respondents were encouraged to clear their doubts regarding the questionnaire and once the respondent had finished answering, each questionnaire was checked to see if they had filled in the questionnaire completely. Data were tabulated into frequency and percentage to find correlation studies between the characteristics, perceived susceptibility, and self-efficacy on Pap smear uptake. Pearson chi-squared test was used to find a correlation in this study. This study was carried out with ethical clearance from the Health Research Ethics Committee Faculty of Medicine, Universitas Padjadjaran.

\section{Results}

This study was to identify the presence Out of 337 female lecturers working in Faculty of Medicine Universitas Padjadjaran, only 79 were participated in this study, consisting of lecturers in medicine and midwifery. The majority of the medical lecturers were middleaged with a master degree as the highest level of education. Most of them were married with duration of more than 5 years and the number of children was less than 3 (Table 1).

The data revealed that only half of the respondents had taken Pap smear and only half of them had it done 3 times or more. The majority of the respondents in this study had taken their previous Pap smear more than 2 years ago and a large number of them stated that they did not routinely get screened for cervical cancer. Government hospital and private practice clinic was the most frequent place responded by the participants for Pap smear uptake (Table 2).

Among all the respondents, only a minority of medical lecturers $(12.70 \%)$ had HPV vaccinated; whereas the remaining respondents who did not take HPV vaccination stated a factor of 'time' as the barrier to vaccination. The risk perception of respondents on cervical cancer was mostly answered as 'no'.

The majority of the study subjects were willing to do Pap smear for screening routinely. In this study, a large number of lecturers took Pap smear as early screening and did it by their means; while the lecturers who did not get screened stated that time was the barrier to take routine screening (Table 3 ).

There was a significant correlation between 
Table 1 The Characteristic of Female Medical Lecturers from Faculty of Medicine, Unviersitas Padjadjaran

\begin{tabular}{|c|c|c|}
\hline Characteristic & $\mathbf{n}$ & $\%$ \\
\hline \multicolumn{3}{|l|}{ Age } \\
\hline Mean \pm SD & $44.21 \pm 11.95$ & \\
\hline \multicolumn{3}{|l|}{ Age category (years) } \\
\hline $20-30$ & 5 & 6.3 \\
\hline $31-40$ & 40 & 50.6 \\
\hline $41-50$ & 6 & 7.6 \\
\hline $51-60$ & 17 & 21.5 \\
\hline$>60$ & 11 & 13.9 \\
\hline \multicolumn{3}{|l|}{ Level of Education } \\
\hline Medical Doctor & 21 & 26.6 \\
\hline Master degree & 52 & 65.8 \\
\hline Ph.D degree & 6 & 7.6 \\
\hline \multicolumn{3}{|l|}{ Marital Status } \\
\hline Married & 76 & 96.2 \\
\hline Divorced & 1 & 1.27 \\
\hline Deceased & 2 & 2.53 \\
\hline \multicolumn{3}{|l|}{ Duration of Marriage } \\
\hline$<5$ years & 11 & 13.9 \\
\hline 5-10 years & 22 & 27.8 \\
\hline$>10$ years & 46 & 58.2 \\
\hline \multicolumn{3}{|l|}{ Number of children } \\
\hline No children & 2 & 2.5 \\
\hline 1 & 13 & 16.5 \\
\hline 2 & 39 & 49.4 \\
\hline 3 & 20 & 25.3 \\
\hline 4 & 4 & 5.1 \\
\hline 5 & 1 & 1.3 \\
\hline
\end{tabular}

Note: Phd=Doctorate of Philosophy

age, level of education and duration of marriage with the uptake of Pap smear. However, perceived susceptibility and self-efficacy showed no correlation with the uptake of Pap smear among medical lecturers (Table 4).

\section{Discussion}

An efficient way to prevent cervical cancer is by screening as early detection, and this is done by performing a Pap smear onto a patient. ${ }^{7}$ The sole function of this test is to examine and to identify pre-cancerous changes in the cervix. ${ }^{11}$ In previous research, the Pap test has reduced death rates among women in developing countries, while HPV vaccination has been proven to be effective against cervical cancer although it may not prevent all cases of cervical cancer.,12 Therefore, it is still crucial for women to get routine Pap smear although they have been vaccinated or are not at risk.7,10

This study finding has shown that only $12.7 \%$ of medical faculty lecturers have taken HPV vaccination and only $55.7 \%$ have taken 
Table 2 The Practice of Pap Smear Screening among Medical Lecturers from Faculty of Medicine, Unviersitas Padjadjaran

\begin{tabular}{|c|c|c|}
\hline & $\mathbf{n}$ & $\%$ \\
\hline \multicolumn{3}{|l|}{ Ever taken Pap smear } \\
\hline Yes & 44 & 55.7 \\
\hline No & 35 & 44.3 \\
\hline \multicolumn{3}{|l|}{ Risk perception of cervical cancer } \\
\hline Yes & 25 & 31.6 \\
\hline No & 54 & 68.4 \\
\hline \multicolumn{3}{|l|}{ Frequency of Pap smear uptake $(n=44)^{*}$} \\
\hline Once & 9 & 20.5 \\
\hline Twice & 12 & 27.3 \\
\hline 3 Times & 9 & 20.5 \\
\hline$>3$ Times & 14 & 31.8 \\
\hline \multicolumn{3}{|l|}{ Previous Pap smear exam $(n=44) *$} \\
\hline$<1$ year ago & 6 & 13.6 \\
\hline $1-2$ years ago & 21 & 47.7 \\
\hline $2-3$ years ago & 5 & 11.4 \\
\hline$>3$ years ago & 9 & 20.4 \\
\hline Don't remember & 3 & 6.8 \\
\hline \multicolumn{3}{|l|}{ The regularity of Pap smear uptake $(n=44) *$} \\
\hline Once in a year & 12 & 27.3 \\
\hline Twice in a year & 3 & 6.8 \\
\hline Three times in a year & 1 & 2.3 \\
\hline Did not do routinely & 28 & 63.6 \\
\hline \multicolumn{3}{|l|}{ A Place to get Pap smear $(n=44)^{*}$} \\
\hline Government hospital & 12 & 27.3 \\
\hline Government hospital and private practice clinic & 4 & 9.1 \\
\hline Government hospital and Laboratory & 5 & 11.4 \\
\hline Private practice clinic & 17 & 38.6 \\
\hline Private practice clinic and Laboratory & 1 & 2.3 \\
\hline Laboratory & 4 & 9.1 \\
\hline Others & 1 & 2.3 \\
\hline
\end{tabular}

Note: * data only taken from 44 respondents, others did not answer.

Pap smear. The reason for a low number of getting HPV vaccination is due to lack of time, while $31.6 \%$ state that they are not at risk. The result is similar to other studies conducted concerning the uptake of the HPV vaccine; the barriers to vaccination are regarding the adverse reaction of the vaccine and the perception of having a low risk towards cervical cancer. ${ }^{13}$

In this study, the majority of the lecturers perceive themselves as having low risk for cervical cancer, and this could be one of the reasons why the screening uptake is low. This finding could influence the screening uptake for cervical cancer by using the health belief model that states perceived risk could 
Table 3 The Willingness to Have Cervical Cancer Screening among Medical Lecturers from Faculty of Medicine Unviersitas Padjadaran

\begin{tabular}{lcc}
\hline & $\mathbf{n}$ & $\mathbf{\%}$ \\
\hline $\begin{array}{l}\text { Willingness to have cervical cancer screening } \\
\text { routinely }\end{array}$ & \\
$\quad$ Yes & 67 & 84.8 \\
$\quad$ No & 12 & 15.2 \\
Reason for taking Pap smear & & \\
Recommended by doctor & 1 & 2.3 \\
Check up & 8 & 18.2 \\
Early screening & 34 & 77.3 \\
Recommended by friend & 1 & 2.3 \\
Reason for not taking Pap smear & & \\
No time & 27 & 77.1 \\
Not at risk & 8 & 22.9 \\
Influence or recommendation to get Pap smear & & \\
Husband/partner & 4 & 9.1 \\
Doctor & 9 & 20.5 \\
Doctor and colleague & 2 & 4.5 \\
Colleague & 5 & 11.4 \\
No one & 21 & 47.7 \\
Others & 3 & 6.8 \\
\hline
\end{tabular}

influence the behavior of an individual. ${ }^{10}$

A total of 58 of $79(73.4 \%)$ respondents in this study hold a master's or Ph.D degree as their highest level of education, showing that the majority of the population have high level of education which should lead to good knowledge regarding the disease, as well as high awareness of its risk factors and preventive measures. However, in this study, the uptake for cervical cancer screening and HPV vaccination is low among respondents (Table 1). In contrast, a study conducted in India12 among rural women showed that women who are more aware of the disease are more likely to get screened for cervical cancer compared to women with poor knowledge about the disease.

Most of the respondents have less than 3 children from their marriage while only 1 respondent has 5 children from their marriage. A study conducted on the cofactors leading to carcinogenesis of cervical cancer screening has shown that high parity is associated with increased risk of having cervical cancer. ${ }^{14}$ This condition could probably result in that most lecturers in this study perceive that they are not at risk because most of them have a low parity.

Regarding the frequency of obtaining a Pap smear among medical lecturers, less than half had screening more than 3 times in their lifetime and only a total of 21 medical lecturers claimed the last time they have been screened was 1 to 2 years ago. Based on the screening guidelines, women aged 30-69 years old are encouraged to get screened once in 3 years. ${ }^{15}$ Furthermore, this study found that most of the medical faculty lecturers did not get screened routinely due to their busy schedule in finding time to go for screening. In the health belief model, the perceived barrier is one of the factors that can influence individual behavior. In a similar study conducted among postgraduate women, it is reported that lack of time is the main reason for the barrier of screening. ${ }^{10}$

This study assessed the place where Pap smear was taken and found that most of the 
Table 4 Correlation between the Characteristics and the Pap smear uptake

\begin{tabular}{|c|c|c|c|c|}
\hline \multirow{2}{*}{ Characteristics } & \multicolumn{2}{|c|}{ Pap smear Uptake } & \multirow{2}{*}{$\begin{array}{l}\text { Pearson } \\
\text { Correlation }\end{array}$} & \multirow{2}{*}{ p-value } \\
\hline & Yes & No & & \\
\hline \multicolumn{5}{|l|}{ Age (years old) } \\
\hline$<35$ & 3 & 16 & 16.146 & $0.001^{*}$ \\
\hline$\geq 35$ & 41 & 19 & & \\
\hline \multicolumn{5}{|l|}{ Level of education } \\
\hline Medical Doctor & 6 & 15 & 8.529 & $0.003^{*}$ \\
\hline Master's/PhD & 38 & 20 & & \\
\hline \multicolumn{5}{|l|}{ Marital status } \\
\hline Married & 43 & 33 & 0.624 & 0.581 \\
\hline Divorced/Deceased & 1 & 2 & & \\
\hline \multicolumn{5}{|l|}{ Duration of marriage(years) } \\
\hline$\leq 10$ & 8 & 25 & 22.723 & $0.001^{*}$ \\
\hline$>10$ & 36 & 10 & & \\
\hline \multicolumn{5}{|l|}{ Number of children } \\
\hline$\leq 2$ & 29 & 25 & 0.275 & 0.600 \\
\hline$>2$ & 15 & 10 & & \\
\hline \multicolumn{5}{|c|}{$\begin{array}{l}\text { Perceived Susceptibility Risk of having } \\
\text { cervical cancer }\end{array}$} \\
\hline Yes & 10 & 15 & 3.652 & 0.056 \\
\hline No & 34 & 20 & & \\
\hline \multicolumn{5}{|l|}{ Self-efficacy HPV vaccine } \\
\hline Yes & 4 & 6 & 1.129 & 0.325 \\
\hline No & 40 & 29 & & \\
\hline \multicolumn{5}{|c|}{ Willingness to take Pap smear routinely } \\
\hline Yes & 40 & 27 & 2.868 & 0.090 \\
\hline No & 4 & 8 & & \\
\hline
\end{tabular}

Note : ${ }^{*}$ statistically significant at $\mathrm{p}<0.05$.

respondents took Pap smear in a private practice clinic and government hospital. These two places were popular among medical faculty lecturers due to the convenience of the location and the facility. Moreover, among respondents who had not taken Pap smear, 27 of them stated they had no time. This could be due to the time constraint that they faced or because of their heavy workload. A previous study done in England ${ }^{16}$ has shown similar findings in which the women respond that time constraint is one of their limitations for Pap smear screening.

The willingness to be screened routinely in this study was high, accounting for $84.8 \%$.
The large percentage of willingness to be screened could be influenced by knowledge of the importance of cervical cancer test which can influence screening behavior in women. ${ }^{10}$ The remaining $15.2 \%$ of respondents who did not want to be screened could result in believing that they were not at risks, such as having their partner or husband deceased. According to a study relating the health belief model to cervical cancer screening, it is stated that one of the reasons for not participating in Pap smear was the belief that the individuals were not at risk of cervical cancer. ${ }^{10}$ Therefore, this could be one of the factors influencing the uptake of cervical cancer screening among 
medical faculty lecturers.

Most of the respondents claimed that 'no one' provided recommendations for taking Pap smear, which interprets that it is their initiatives for the screening uptake. This strong self-motivation to undergo screening could be caused by their high level of education.

Correlation between characteristics of respondents, perceived susceptibility, and selfefficacy with the uptake of Pap smear has been assessed. The findings in this study showed a high correlation $(p=0.001)$ between the ages of respondents with the uptake of Pap smear. A previous study conducted on correlating practice and knowledge on cervical cancer revealed that women aged more than 35 were likely to take Pap smear compared to younger women. ${ }^{12}$ This study also showed a correlation between levels of education with Pap smear screening among medical faculty lecturers $(\mathrm{p}=0.003)$, similar to a study among Indian community women, affirming that knowledge has a high significance with screening uptake among women. ${ }^{12}$ Furthermore, marital status in respondents did not correlate with the screening uptake. In comparison to a previous study, it shows that marital status has significance in the uptake of Pap smear. ${ }^{17}$

Duration of marriage among respondents in the study was correlated to the Pap smear uptake $(p=0.001)$, comparable to a study conducted in Qatar ${ }^{18}$ which revealed that women who were married longer were more likely to get screened for cervical cancer. Parity among respondents showed no correlation with taking Pap smear $(\mathrm{p}=0.600)$, it contrasted to a study that showed a high significance between parity and screening uptake. ${ }^{18}$ The reason for low uptake in women with parity was because most respondents had only $2-3$ children and therefore perceived that they had lower risk towards cervical cancer and perceived that they did not require the test.

Perceived susceptibility was evaluated among the respondents by correlating the risk of contracting cervical cancer with the screening uptake. The result showed that there was no correlation between perceived susceptibility and uptake of Pap smear among the medical lecturers $(p=0.056)$. The health belief model states that the beliefs of an individual contracting a disease will influence their screening uptake. ${ }^{10}$ Thus, in our study, medical faculty lecturers who are well informed about the disease perceived low risk of having cervical cancer which influenced their uptake of Pap smear.

Self-efficacy in respondents was assessed by correlating HPV vaccination and willingness to be routinely screened with the uptake of cervical cancer among medical faculty lecturers. Self-efficacy is based on personal behavior, their perception of being at risk, the barriers to screening, which will eventually determine the screening. ${ }^{10}$ In this study, it showed no correlation between self-efficacy and the uptake of Pap smear. Vaccination for HPV vaccine was not correlated with the uptake of Pap smear $(p=0.325)$. Although the findings of this study showed a willingness to routinely screened for Pap smear was satisfactory, however, it was not significantly correlated with the uptake of Pap smear $(p=0.090)$, this result related to the reason that the main barrier for regular screening among the respondents was mostly due to time constraint.

The limitation of this study was the low response rate from the respondents to participate in the study and also the limited time for the researcher to complete the study.

In conclusion, the findings found in this study show that most of the female medical lecturers perceive themselves as having no risk of cervical cancer and in most of them, time was the barrier for screening uptake. Furthermore, age, level of education and duration of marriage are highly correlated with Pap smear uptake.

Therefore, government hospitals or private hospitals should promote Pap smear screening regularly to increase the uptake of screening among doctors. Gynecologists play an important role in encouraging their colleagues to undergo screening and the benefits of it. The awareness for screening should be promoted among female doctors so that they will be more aware of screening practices and furthermore they will be able to schedule a time for screening.

\section{References}

1. Joy T, Sathian B, Bhattarai C, Chacko J. Awareness of cervix cancer risk factors in educated youth: a crosssectional,questionnaire based survey in India, Nepal, and Sri Lanka. Asian Pac J Cancer Prev. 2011;12(7):1707-12.

2. Centers for Disease Control and Prevention. Gynecological cancers: basic information. [Cited 2019 October 9] Available from: <http://www.cdc.gov/ cancer/gynecologic/basic_info/index. htm>.

3. Singh S, Badaya S. Factors influencing 
uptake of cervical cancer screening among women in India: a hospital based pilot study. J Community Med Health Educ. 2012;2(6):1-6.

4. Aziz MF. Gynecological cancer in Indonesia. J Gynecol Oncol. 2009; 20(1):8-10.

5. Saha A,Chaudhary AN, Bhowmik P, Chatterjee $\mathrm{R}$. Awareness of cervical cancer among female students of premier colleges in Kolkata, India. Asian Pac J Cancer Prev. 2010;11(4):1085-90.

6. Makwe CC, Anorlu RI. Knowledge of and attitude toward human papillomavirus infection and vaccines among female nurses at a tertiary hospital in Nigeria. Int J Womens Health. 2011;3:313-7.

7. American Cancer Society. Cervical cancer. [Cited 2019 October 9] Available from: http://www.cancer.org/content/cancer/ en/cancer/cervical-cancer.html.

8. Mahajan SM, Jadhav VS, Magane AR, Adchitre SA, Salve SB. Awareness and screening practices of cervical cancer among nursing staff working in tertiary care hospital. Int J Community Med Public Health. 2017;4(10):3590-5.

9. Ndejjo R, Mukama T, Musabyimana A, Musoke D. Uptake of cervical cancer ccreening and associated factors among women in Rural Uganda: A cross sectional study. PloSOne. 2016;11(2):e0149696.

10. Tavafian SS. Predictors of cervical cancer screening: an application of health belief model. In: Rajamanickam R, editor. Topics on servical cancer with an advocacy for prevention. $1^{\text {st }}$ Ed. London: InTech Publisher; 2012. p. 1-24.

11. Tacken MA, Braspenning JC, Hermens RP, Spreeuwenberg PM, van der Hoogen HJ, de Bakker DH, et al. Uptake of cervical cancer screening in The Netherlands is mainly influenced by women's beliefs about the screening and by the inviting organization.
Eur J Public Health. 2007;17(2):178-85.

12. Albrow R, Blomberg $K$, Kitchener $H$, Brabin L, Patnick J, Tishelman C et al. Interventions to improve cervical cancer screening uptake amongst young women: A systematic review. Acta Oncol. 2014;53(4):445-51.

13. Ashwathy S, Quereshi MA, Kurian B, Leelamoni K. Cervical cancer screening: current knowledge \& practice among women in a rural population of Kerala, India. Indian J Med Res. 2012;136(2):205-10.

14. Cassidy B,Schlenk EA. Uptake of human pappilomavirusvaccine:areview ofliterature and report of a quality assurance project. J Pediatr Health Care. 2012;26(2):92-101.

15. Tasic D, Lazarevic I, Knezevic A, Tasic L, Pikula A, Perisic Z et al. The impact of environmental and behavioural cofactors on the development of cervical disorders in HR-HPV-infected women in Serbia. Epidemiol Infect. 2018;146(13):1714-23.

16. Canadian Task Force on Preventive Health Care. Recommendations on screening for cervical cancer. CMAJ. 2013;185(1):35-45.

17. Waller J, Bartoszek M, Marlow L, Wardle J. Barriers to cervical cancer screening attendence in England: a population-based survey. J Med Screen. 2009;16(4):199-204.

18. Jelastopulu E, Karnaki P, Bartsokas C, Plotas P, Sissouras A. Screening for cervical cancer-uptake and associated factors in a representative sample in the city of Patras,West-Greece. Universal Journal of Public Health. 2013;1:7-13.

19. Al-Meer FM, Aseel MT, Al-Khalaf J, AlKuwari MG, Ismail MF. Knowledge, attitude and practices regarding cervical cancer screening among women visiting primary health care in Qatar. East Mediterr Health J. 2011;17(11):855-61. 